\title{
Potential association of vitamin D in preventing COVID-19
}

\author{
Delia Nica-Badea ${ }^{1}$, Tudor Pungan ${ }^{2}$ \\ 1"Constantin Brâncuși" University of Târgu-Jiu, Faculty of Medical and Behavioral Sciences, \\ No. 4, Tineretului St., Târgu-Jiu, Romania \\ ${ }^{2}$ Tudormed SRL, No 1B, 23 August St., Târgu-Jiu, România \\ E-mail: nicabadeadelia@yahoo.com
}

\begin{abstract}
This paper presents the role of vitamin D in the body, namely: calcium absorption, maintaining muscle function, but also in strengthening the immune system. Vitamin D exerts its biological functions dependent on vitamin D receptor (VDR), which is a member of the superhuman family of nuclear hormone receptors and clearly expressed in a wide variety of cells. Vitamin D is mainly obtained by synthesizing Vitamin D3 in our skin using ultraviolet light B (UVB) and in small amounts from food sources. Respiratory epithelial cells can convert vitamin $\mathrm{D}$ to the active form and that vitamin D metabolites increase the cytokines involved in immunity in response to respiratory viruses. Studies have shown that the most vulnerable population group for COVID - 19 is also the one with the highest vitamin D deficiency.

Keywords: vitamin D, metabolism, prevention, COVID-19.
\end{abstract}

\section{Vitamin D: synthesis and metabolic pathways}

Vitamin D is the name given to a wider group of vitamins. Vitamin D2 (ergocalciferol, which is found in plants) and vitamin D3 (cholecalciferol, which is found in animal tissues) are inactive pharmacological forms that can be metabolically converted into active compounds by hydroxylation in the liver and then in the kidneys.

The liver converts vitamin D3 into 25-hydroxycholecalciferol, which is weakly active. The kidneys then convert this compound to either 24,25-dihydroxycholecalciferol, which is also weakly active, or $1 \alpha, 25$-dihydroxycholecalciferol, the most active form of vitamin D [1] (Figure 1).

Vitamin D is important for bone metabolism and regulates calcium levels in the blood, increases the absorption of calcium from the intestine and reduces the amount lost by the kidneys. Many tissues have vitamin D receptors, and vitamin D may have other roles [2]. 


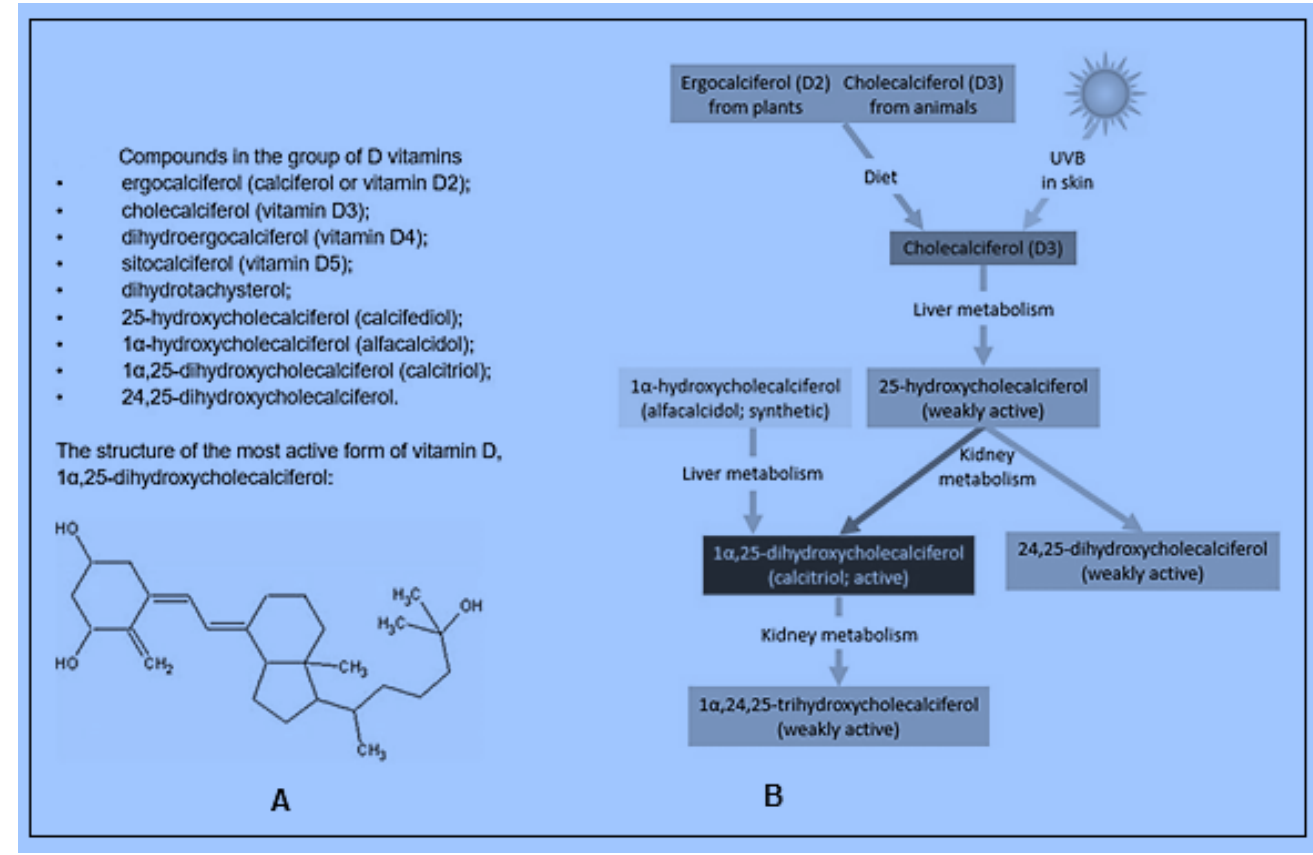

Figure 1. Vitamin D: A. Compounds of the vitamin D group; B. Metabolic pathways in the body

The role of vitamin D in the body is to absorb calcium and in maintaining muscle function, but also in strengthening the immune system, say experts from Cleveland Clinic, (USA). Its concentration in the skin depends on a number of factors, including the amount of vitamin D that the body produces in the epithelial tissue due to the sun's rays. Essentially, this is to be completed at the time of day, the season and the latitudes (Central or Northern Europe), [3].

Vitamin D exerts its biological functions dependent on vitamin D receptor (VDR), which is a member of the superhuman family of nuclear hormone receptors and clearly expressed in a wide variety of cells. While vitamin D / VDR signaling is known for its effect on bone homeostasis, its suppressive regulation of the inflammatory response is becoming increasingly attractive [4]. It has long been established that vitamin D / VDR signaling regulates duodenal transport of transcellular calcium. Recent studies have shown that intestinal epithelial VDR plays a key role in protecting the integrity of the mucosal barrier. The intestine is one of the tissues in the body that has the most abundant VDR expression.

\section{Sources of vitamin D}

Vitamin D is mainly obtained by the synthesis of Vitamin D3 in our skin using ultraviolet light B (UVB) and in small amounts from food sources (Figure 1). In countries with high latitudes, UVB in winter is not enough to synthesize the optimal need, so oral intake becomes more important. Dietary sources include products of animal origin, such as fatty fish, red meat, liver and egg yolks, as well as fortified foods such as infant formula, breakfast cereals and margarines. Some fungi can provide vitamin D if grown under ultraviolet light [5]. The Scientific Advisory Committee on Nutrition (SACN) recommends a daily intake of $10 \mu \mathrm{g}$ (micrograms) (400 international units / day) for all four-year-olds living in the UK to ensure musculoskeletal health [6], and for adults, the standard dose of vitamin D deficiency prevention is $10 \mu \mathrm{g}$ (400 IU) daily [7].

\section{Vitamin D deficiency}

Vitamin D deficiency is very common, especially in winter. Vitamin D is usually measured in blood serum in the relatively stable form of 25-hydroxycholecaliferol (25 (OH) D3). In the UK, $25 \mathrm{nmol} / \mathrm{L}$ $(10 \mathrm{ng} / \mathrm{ml})$ is used as a reduction for deficiency, but there is no universally agreed definition, so clinical trials have used different values to define vitamin D deficiency. [6] 
People at high risk of disability:

- Infants and children under four years of age;

- Pregnant and lactating women, especially adolescents and young women;

- People over 65;

- People who have little or no exposure to the sun, for example, those who cover their skin for cultural reasons and those who are covered in or inside the house for long periods;

- People with darker skin, for example, people of African, African-Caribbean or South Asian descent.

\section{Opportunity for vitamin D supplement in COVID-19}

There is in vitro evidence that vitamin $\mathrm{D}$ is involved in immune cell responses to some viral and bacterial respiratory pathogens. Vitamin D appears to regulate genes involved in immune cell responses that are exposed to Streptococcus pneumoniae [8].

There are laboratory studies that show that respiratory epithelial cells can convert vitamin $\mathrm{D}$ to the active form and that vitamin D metabolites increase the cytokines involved in immunity in response to respiratory viruses. However, vitamin D metabolites do not appear to prevent viral replication in cell cultures $[9,10]$.

\section{Evidence of the vitamin D - COVID-19 correlation}

There are opinions that people with low serum vitamin D may have a higher risk of COVID-19 infection or worsen if infected [11]. There is also an overlap between the high-risk groups of vitamin D deficiency and the high-risk groups of severe COVID-19. Examples include people with chronic illness, old age and people with black and minority ethnic heritage (BAME). However, infants and children are at risk of vitamin D deficiency, but are not considered at high risk for severe COVID-19 [12].

On 10 April 2020, the UK National Center for Intensive Care Audit and Research (ICNARC) reported that $31 \%$ (310/993) of patients in need of advanced respiratory support defined their ethnicity in a white category compared to $24 \%$ of patients (99/408) receiving basic respiratory support [13]. These data are intriguing, but we must be careful about their over-interpretation.

If vitamin $\mathrm{D}$ has a role in preventing or mitigating the effects of COVID-19 infection, supplementation would be a cheap and low-risk intervention. Therefore, we aimed to review the clinical evidence that vitamin D has a role in the prevention or treatment of COVID-19.

\section{A) Planned studies}

With PubMed and Google Scholar as a source, several studies have been found that are registered, but have not been reported yet. None seemed to be masked compared to placebo.

o A study with vitamin D3 plus zinc, compared to regular care, is planned in an open-label randomized controlled trial (RCT) in adults over 60 who are "institutionalized" but asymptomatic [14]. The dose of vitamin D3 is $2000 \mathrm{IU}(50 \mu \mathrm{g})$ plus $30 \mathrm{mg}$ of zinc gluconate per day for two months. The main measure of outcome is mortality; the incidence of COVID-19 infection is a secondary outcome.

o One study tests whether a single oral dose of 25,000 IU (625 $\mu \mathrm{g}$ ) of vitamin D (form not specified) will improve mortality in patients infected with SARS-CoV-2, but has no severe symptoms compared to regular care [15]. The reason is based on veterinary findings that low levels of vitamin $\mathrm{D}$ in calves have been associated with bovine coronavirus infection.

o Another RCT will compare single doses of vitamin D3, 50,000 IU to 200,000 IU (1250 Vs 5000 $\mu \mathrm{g}$ ) in people with COVID-19 pneumonia who are over 75 years old or over 70 with low oxygen saturation; the main measure of outcome is mortality at 14 days [16].

A single open-label study uses a combination of hydroxychloroquine, vitamins $\mathrm{C}$ and $\mathrm{D}$ (unspecified form) and zinc as prophylaxis in health workers who are healthy and at risk of COVID-19, by exposure to infected patients [17].

The same investigator recorded another study, which will provide all participants with hydroxychloroquine, vitamins $\mathrm{C}$ and $\mathrm{D}$ (unspecified form) and zinc plus azithromycin, in order to determine whether this combination can effectively treat COVID-19 [18]. It is not clear how these studies will meet their stated objectives without comparison groups. 


\section{B) Reported studies}

The Seneca study reported mean serum D value in the elderly in a number of European countries compared to severe deficiency defined as a $25(\mathrm{OH}) \mathrm{D}$ serum less than $30 \mathrm{nmol} / \mathrm{L}$ [19]. Such values are reported as follows: $26 \mathrm{nmol} / \mathrm{L}$ in Spain, $28 \mathrm{nmol} / \mathrm{L}$ in Italy and $45 \mathrm{nmol} / \mathrm{L}$ in the Nordic countries. In Switzerland, average vitamin D levels are $23(\mathrm{nmol} / \mathrm{L})$ in nursing homes, and in Italy, $76 \%$ of women over the age of 70 have found that they have circulating levels below 30nmol / L [219]. These are the countries with a large number of cases of COVID - 19, and the elderly are the group with the highest risk of morbidity and mortality with SARS-Cov2. The study concludes that significant relationships were found between vitamin D levels and the number of COVID-19 cases, but especially the mortality caused by this infection.

The most vulnerable population group for COVID-19 is also the one with the highest vitamin D deficiency. The authors believe that we can recommend vitamin $\mathrm{D}$ supplementation to protect against COVID-19 infection.

Vitamin D has already been tested as a protector against acute respiratory infections and has been shown to be safe. Martineau A.R. et al. (2017), concluded in a meta-analysis that vitamin D supplementation was safe and protective against acute respiratory tract infections. They described that patients with severe vitamin D deficiency showed the greatest benefit [20].

The importance of vitamin D deficiency is shown by a recently published analysis of COVID-19 deaths in 780 COVID-19 patients in Indonesia [21].

Table 1 illustrates that old age (old age), comorbidities and vitamin D deficiency or insufficiency have been associated with increasing chances of death. Based on these data, the plasma level of vitamin $\mathrm{D}$ is an independent precursor of mortality.

Table 1. Data of patients with COVID-19 related to vitamin D levels and disease outcome.

\begin{tabular}{|l|l|l|l|}
\hline & Vitamin D: $<20 \mathrm{ng} / \mathrm{ml}$ & $20-30 \mathrm{ng} / \mathrm{ml}$ & $>30 \mathrm{ng} / \mathrm{ml}$ \\
\hline Overall, N & 179 & 213 & 388 \\
\hline Mean age & $66.9 \pm 13.8$ & $62.9 \pm 14.7$ & $46.6 \pm 12.6$ \\
\hline Comorbidity, \% & 80.0 & 73.8 & 18.8 \\
\hline Death, \% & 98.9 & 87.8 & 4.1 \\
\hline Active, \% & 1.1 & 12.2 & 95.9 \\
\hline $\begin{array}{l}\text { Odds ratio } \\
\text { Adjusted for age, sex and comorbidity }\end{array}$ & $10.12(\mathrm{p}<.001)$ & $7.63(p<.001)$ & \\
\hline
\end{tabular}

Recently, a number of 8 studies have begun to test the effect of vitamin D supplementation at various doses (up to 200,000 IU) during COVID-19 disease. The aim is to clarify whether vitamin D supplementation at different doses has an influence on the course of the disease or, in particular, on the immune response, or whether it can prevent the development of acute respiratory distress syndrome (ARDS) or thrombosis [22].

A recent study (E Laird. May 2020) [23] assumes that vitamin D status may influence the severity of Covid-19 responses and that the prevalence of vitamin D deficiency in Europe will be closely aligned with Covid-19 mortality. The calculated mortality rate of Covid-19 (per million) in European countries according to the average concentration of $25(\mathrm{OH}) \mathrm{D}$ is shown in Figure 2.

The correlation between the concentration of $25(\mathrm{OH}) \mathrm{D}$ and the mortality rate has a conventional significance $(\mathrm{P}=0.046)$ of Spearman's rank correlation. 


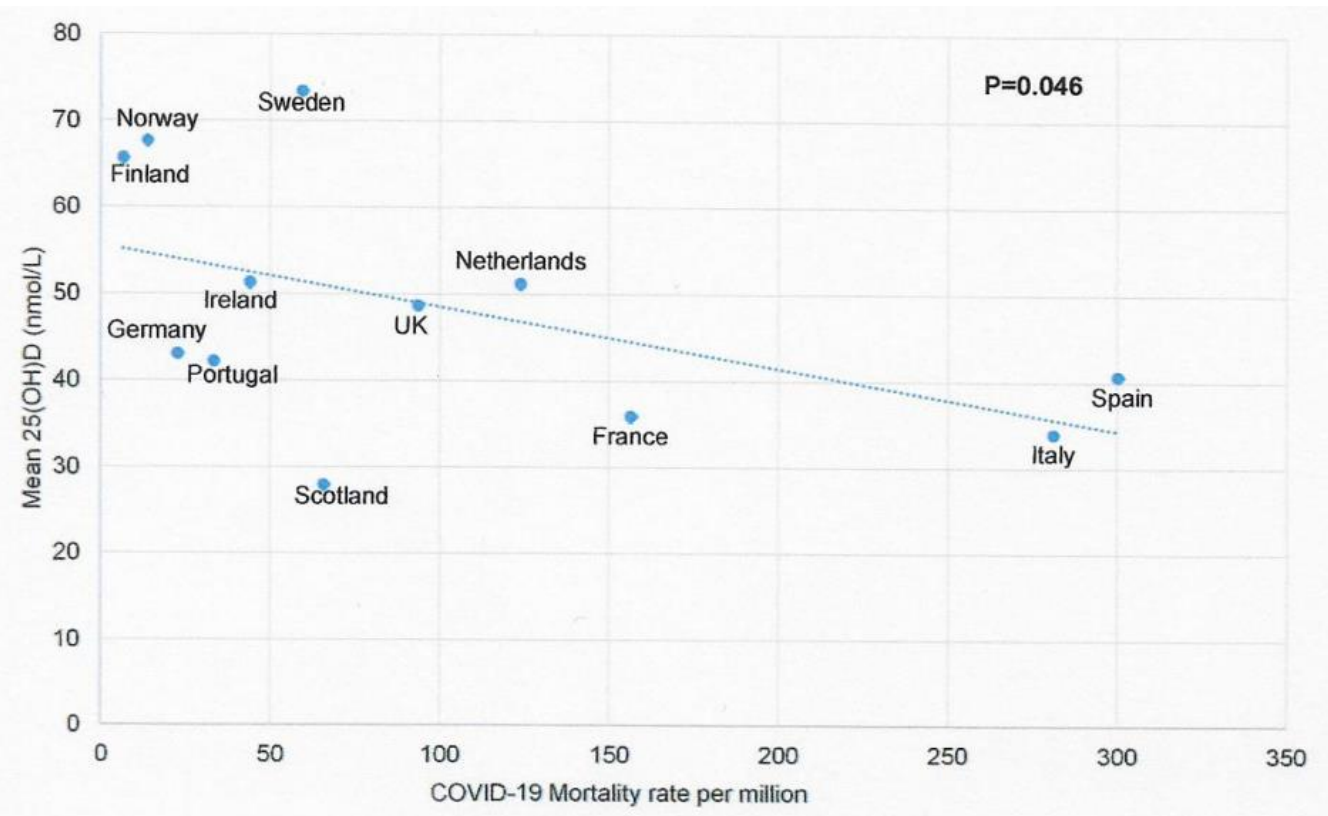

Figure 2. Mortality rate for a number of countries in relation to vitamin D levels (conc. Averages)

\section{Conclusion}

An inadequate intake of vitamin D has a variety of skeletal and non-skeletal effects. There is ample evidence that various noncommunicable diseases (high blood pressure, diabetes, CVD, metabolic syndrome) are associated with low levels of vitamin $\mathrm{D}$ in plasma. These comorbidities, together with the often concomitant vitamin D deficiency, increase the risk of severe COVID-19 events. More attention should be paid to the importance of vitamin D status for the development and evolution of the disease.

In particular, in the methods used to control the pandemic (blockage), the skin's natural synthesis of vitamin D is reduced when people have few opportunities to be exposed to the sun. Specific dietary advice, moderate supplements or fortified foods can help prevent this deficiency.

\section{References}

[1] Grahame-Smith DG, Aronson JK. The Oxford Textbook of Clinical Pharmacology and Drug Therapy. Oxford: Oxford University Press; 2002.

[2] Hansdottir S, Monick M, Hinde S, Lovan N, Look D, Hunninglake G. Respiratory Epithelial Cells Convert Inactive Vitamin D to its Active Form. J. Immunol. 2008; 181: 7090-7099

[3] Heike A, Ferrari B, Shao A, Hughes BD, Hathcock J, Giovannucci E et al. Benefit - Risk Assessment of Vitamin D Supplementation. Osteoporos Int. 2010; 21(7): 1121-1132.

[4] Michael F., Holick P., The Death D-fying Vitamin.Mayo Clin Proc.nJune 2018;93(6):679 681 nhttps://doi.org/10.1016/j.mayocp.2018.04.014www.mayoclinicproceedings.orgna2018 Mayo Foundation for Medical Education and Research

[5] Cardwell G, Bornman JF, James AP, Black LJ. A review of mushrooms as a potential source of dietary vitamin D. Nutrients 2018; 10: 1-11.

[6] Public Health England. Vitamin D and Health 2016 [Internet]. Sci. Advis. Comm. Nutr. 2016 Available from: https://www.gov.uk/government/publications/sacn-vitamin-d-and-healthreport.

[7] Joint Formulary Comittee. British National Formulary [Internet]. London: BMJ Group and Pharmaceutical Press; 2019, available from:

https://bnf.nice.org.uk/drug/colecalciferol.html\#indicationsAndDoses 
[8] Olliver M, Spelmink L, Hiew J, Meyer-Hoffert U, Henriques-Normark B, Bergman P. Immunomodulatory effects of vitamin $\mathrm{D}$ on innate and adaptive immune responses to Streptococcus pneumoniae. J. Infect. Dis. 2013; 208: 1474-1481.

[9] Hansdottir S, Monick M, Hinde S, Lovan N, Look D, Hunninglake G. Respiratory Epithelial Cells Convert Inactive Vitamin D to its Active Form. J. Immunol. 2008; 181: 7090-7099

[10] Greiller CL, Martineau AR. Modulation of the immune response to respiratory viruses by vitamin D. Nutrients 2015; 7: 4240-4270.

[11] Grant WB, Lahore H, McDonnell SL, Baggerly CA, French CB, Aliano JL, Bhattoa HP. Evidence that Vitamin D Supplementation Could Reduce Risk of Influenza and COVID-19 Infections and Deaths. Nutrients 2020; 12: 988.

[12] Coronavirus (COVID-19): Shielded patients list [Internet]. Available from: https://digital.nhs.uk/coronavirus/shielded-patient-list.

[13] ICNARC. ICNARC report on COVID-19 in critical care. 2020; : 1-9.

[14] Seguy D. Impact of Zinc and Vitamin D3 Supplementation on the Survival of Aged Patients Infected With COVID-19 (ZnD3-CoVici) [Internet]. Available from: https://clinicaltrials.gov/ct2/show/NCT04351490.

[15] Castillo MJ. Vitamin D on Prevention and Treatment of COVID-19 (COVITD-19) [Internet]. NCT04334005 2020. Available from: https://clinicaltrials.gov/ct2/show/NCT04334005.

[16] Annweiler C. COvid-19 and Vitamin D Supplementation: a Multicenter Randomized Controlled Trial of High Dose Versus Standard Dose Vitamin D3 in High-risk COVID-19 Patients (CoVitTrial) [Internet]. 2020. Available from: https://clinicaltrials.gov/ct2/show/record/NCT04344041.

[17] Haza S. A Study of Hydroxychloroquine, Vitamin C, Vitamin D, and Zinc for the Prevention of COVID-19 Infection (HELPCOVID-19) [Internet]. 2020.Available from: https://clinicaltrials.gov/ct2/show/record/NCT04335084.

[18] Haza S. A Study of Quintuple Therapy to Treat COVID-19 Infection (HAZDpaC) [Internet]. 2020.Available from: https://clinicaltrials.gov/ct2/show/NCT04334512

[19] Lips, P., Cashman, K., Lamberg-Allardt, C., Bischoff-Ferrari, H., Obermayer-Pietsch, B., Bianchi, M., Stepan, J., El-Hajj Fuleihan, G., and Bouillon, R. (2019). Current vitamin D status in European and Middle East countries and strategies to prevent vitamin D deficiency: a position statement of the European Calcified Tissue Society. European Journal of Endocrinology 180, 4, P23-P54, available from: 〈https://doi.org/10.1530/EJE-18-0736>

[20] Martineau Adrian R, JolliffeDavid A,Hooper Richard L, Greenberg Lauren, Aloia John F, Bergman Peter et al. Vitamin D supplementation to prevent acute respiratory tract infections: systematic review and meta-analysis of individual participant data BMJ 2017; 356 :i6583 https://www.researchsquare.com/article/rs-21211/v1,

[21] Raharusuna P, Priambada S, Budiarti C, et al. Patterns of COVID-19 Mortality and Vitamin D: An Indonesian Study. April 26, 2020; Available at SSRN: https://ssrn.com/abstract=3585561, doi:10.2139/ssrn.3585561.

[22] https://clinicaltrials.gov/ct2/results?cond=vitamin+D+and+Covid-19 (access 05.20.2020).

[23] E. Laird1, J. Rhodes2, R.A. Kenny1. Vitamin D and Inflammation: Potential Implications for Severity of Covid-19. Ir Med J;may 2020; Vol 113; No. 5; P81 